\title{
99mTC-MDP bone scanning in a subungual
} glomus tumour

\author{
Zahra Kiamanesh, Zakieh Nasiri, Parinaz Jahanpanah, Sara Shakeri, Ramin Sadeghi \\ Nuclear Medicine Research Center, School of Medicine, Mashhad University of Medical Sciences, Mashhad
}

[Received 26 XII 2017; Accepted 17 VII 2018]

\begin{abstract}
A 37-year-old female patient with four months history of paroxysmal pain in the left index finger was referred to our department for ${ }^{99 m}$ TC-MDP scintigraphy. Radiographic studies of the patient showed a lytic tumour in the distal phalanx of the left second finger compatible with a glomus tumour. The scan showed mild decreased activity in the blood pool phase and minimal increased activity on the delayed images. The patient underwent surgery and a glomus tumour was removed. To the extent of our knowledge, this is the first case of bone scan in a glomus tumour of the finger reported in the literature.
\end{abstract}

KEY words: glomus tumour, finger, paroxysmal pain, ${ }^{99 m T c-M D P, ~ b o n e ~ s c a n ~}$

Nucl Med Rev 2018; 21, 2: 111-112

\section{Introduction}

A bone scan is an integral part of diagnostic workup in many primary bone tumours. The scan pattern in various rare tumours has been reported in the literature. However, to the extent of our knowledge, no report exists on bone scan in a glomus tumour.

\section{Case report}

A 37-years-old lady with a painful left index finger was referred to our nuclear medicine department for 99mTC-MDP bone scanning. On clinical history, the patient had severe paroxysmal pain in the index finger of the left hand since 4 months ago. The patient's pain was triggered with tactile stimulation or temperature changes. She also had red-blue discolouration of the finger with thermal variations. There was neither a history of trauma nor the familial history of the similar lesion. On physical examination, she presented nail fold elevation, focal tenderness and finger swelling. According to clinical presentation, glomus tumour had been considered as the most probable diagnosis. Figure 1 shows the hands of the patient. Figure 2 shows the plain radiograph of the fingers.

After the admission of a patient, we injected $740 \mathrm{MBq}(20 \mathrm{mCi})$ of ${ }^{99 m}$ TC-MDP via a lower limb IV line. Imaging was done with a dual head gamma camera with low energy high-resolution collimator and $140 \mathrm{KeV} \pm 10 \%$ photopeak window. Figure 3 shows the 3 phase bone scan of the patient. The patient underwent surgery and the tumour was removed surgically. Pathological examination of the removed tumour was compatible with a glomus tumour.

Correspondence to: Ramin Sadeghi, Nuclear Medicine Research Center, School of Medicine, Mashhad University of Medical Sciences, Mashhad, Iran, e-mail: sadeghir@mums.ac.ir

\section{Discussion}

To the extent of our knowledge, our study is the first reported case of bone scan appearance in glomus tumour. Blood pool images showed decreased uptake and only minimal uptake on the delayed phase was apparent and this is compatible with the abnormal vascular nature of the tumour (with a very slow inflow of blood) and its rapid growth.

In general, glomus tumours are rare tumours which are composed of the modified smooth muscle cells [1]. These cells arise from neurovascular structures responsible for thermostasis and named as glomus body [1]. Glomus tumours occur more commonly in young adult, which account for $1-5 \%$ of soft tissue tumours [1-6].

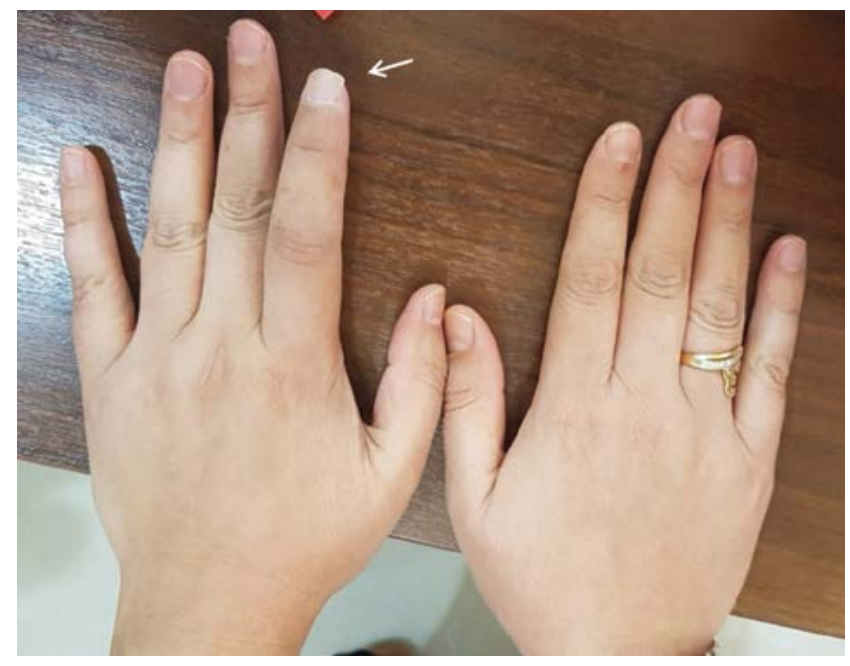

Figure 1. Patient's hand. Note the fusiform shape of the involved finger (arrow) 


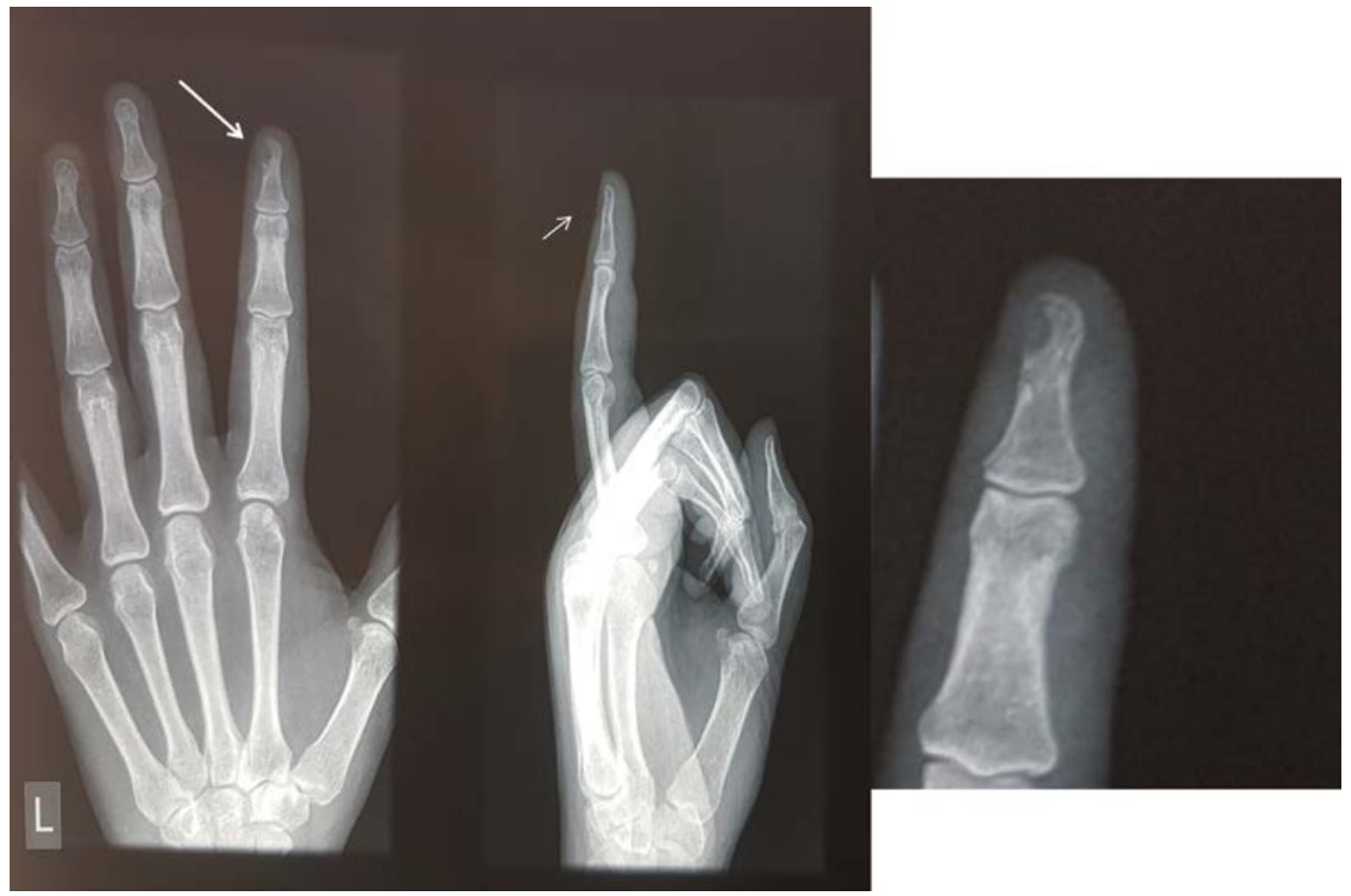

Figure 2. Plain radiographs were performed in anterior and lateral views. On anterior view scalloping of the medial aspect of distal phalanx of the left index finger was noticed (large white arrow). Lateral view radiograph showed thinning of the dorsal aspect of the phalanx (small white arrow). Enlarged radiographic image is presented on the right side of the figure

$\mathbf{R}$

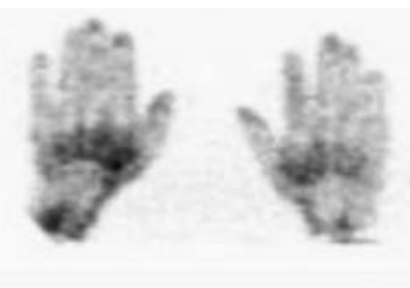

Blood Pool

$\mathbf{R}$

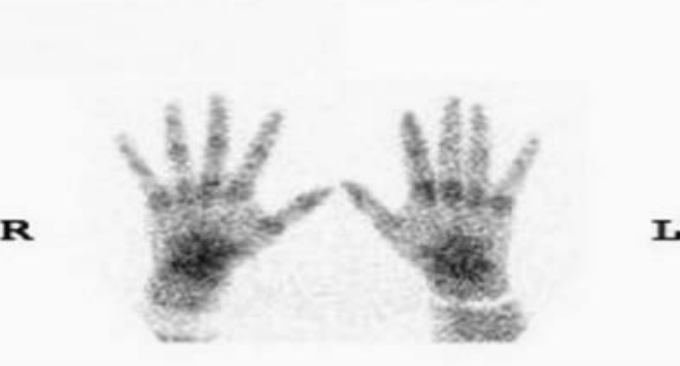

Delayed static

Figure 3. Blood pool image showed mildly decreased uptake in the tip of the left index finger as compared to the opposite side. Delayed images of hands showed minimally increased tracer uptake in the location of a tumour
There was no sex predilection for a glomus tumour, but subungual types are more common among women [2]. Diagnosis is based on clinical history and physical examination [7]. However, imaging methods can be useful to achieve this purpose [7].

\section{References}

1. Greenspan A, Jundt G, Remagen W. Differential Diagnosis in Orthopaedic Oncology. Lippincott Williams \& Wilkins 2007.

2. Fletcher CDM, Unni KK, Mertens F. Pathology and Genetics of Tumours of Soft Tissue and Bone. IARC Press 2002.

3. Girisha BS, Shenoy MM, Mathias M, et al. Glomus tumor of the nail unit. Indian J Dermatol. 2011; 56(5): 583-584, doi: 10.4103/0019-5154.87163, indexed in Pubmed: 22121286.

4. McDermott EM, Weiss APC. Glomus tumors. J Hand Surg Am. 2006; 31(8): 1397-1400, doi: 10.1016/j.jhsa.2006.05.018, indexed in Pubmed: 17027805.

5. Van Ruyssevelt CEA, Vranckx P. Subungual glomus tumor: emphasis on MR angiography. AJR Am J Roentgenol. 2004; 182(1): 263-264, doi: 10.2214/ajr.182.1.1820263, indexed in Pubmed: 14684556.

6. Pandey CR, Singh N, Tamang B. Subungual Glomus Tumours: Is Magnetic Resonance Imaging or Ultrasound Necessary for Diagnosis? Malays Orthop J. 2017; 11(1): 47-51, doi: 10.5704/MOJ.1703.020, indexed in Pubmed: 28435574.

7. Anakwe RE, McEachan JE. A glomus tumour beneath the painful unpolished nail. CMAJ. 2010; 182(12): 1329, doi: 10.1503/cmaj.091645, indexed in Pubmed: 20530165. 